\title{
Органическая химия
}

УДК $547.831 .7+543.51$

DOI: 10.14529/chem160102

\section{ИССЛЕДОВАНИЕ О-ПРОИЗВОДНЫХ \\ 5,7-ДИБРОМ-8-ОКСИХИНОЛИНА МЕТОДОМ ХРОМАТОМАСС-СПЕКТРОМЕТРИИ}

\author{
Д.Г. Ким ${ }^{1}$, А.В. Василенко ${ }^{1}$, А.Б. Мелентьев ${ }^{2}$ \\ ${ }_{1}^{1}$ Южно-Уральский государственный университет, г. Челябинск, \\ 2 Челябинское областное бюро судебно-медицинской экспертизы, г. Челябинск
}

\begin{abstract}
Установлено, что в условиях хроматомасс-спектрометрического исследования 8-аллилокси-5,7-дибромхинолин и 5,7-дибром-8-металлилоксихинолин подвергаются разложению с образованием 7-аллил-5-бром-8-гидроксихинолина и 5-бром-7-металлил8-гидроксихинолина соответственно.

Ключевые слова: 5,7-дибром-8-аллил(металлил)оксихинолин, 5-бром-7аллил(металлил)-8-гидроксихинолин, 5,7-дибром-8-метил(этил)оксихинолин, 5,7-дибром8-пропаргилоксихинолин хроматомасс-спектрометрия, термическая реакиия.
\end{abstract}

\section{Введение}

Целый ряд производных 8-оксихинолина обладают антибактериальной, противогрибковой и противопаразитарной активностью, их применяют в качестве химиотерапевтических и антисептических веществ. В качестве пероральных антибактериальных и антипротозойных препаратов широко используются соединения этой группы, содержащие галоидные заместители (хлор, бром, иод) в положении 5 и 7 хинолинового ядра $[1,2]$. Также производные 8-оксихинолина обладают противораковой активностью [3]. В литературе имеются данные о синтезах некоторых производных 5,7-дибром-8-оксихинолина $[4,5]$, в то же время практически отсутствуют сведения об их масс-спектрах. В базе данных NIST имеется лишь масс-спектр 8-оксихинолина.

Целью данной работы является исследование 5,7-дибром-8-оксихинолина (1), 5,7-дибром-8аллилоксихинолина $\mathbf{( 2 ) ,}$ 5,7-дибром-8-металлилоксихинолина $\mathbf{( 3 ) ,}$ 5,7-дибром-8-пропаргилоксихинолина (4), 5,7-дибром-8-метоксихинолина (5) и 5,7-дибром-8-этоксихинолина (6) методом хроматомасс-спектрометрии (XMC).

\section{Экспериментальная часть}

Масс-спектры электронного удара сняты методом ГХ/MC:

1. Газовый хроматограф 6890 с автосамплером 7683В и масс-селективным детектором 5975В фирмы Agilent Technologies. Условия анализа: колонка HP-5MS длиной 30 м, внутренним диаметром 0,25 мм, с толщиной пленки неподвижной фазы 0,25 мкм, начальная температура колонки $-80{ }^{\circ} \mathrm{C}$, выдержка 1 минуту, увеличение температуры со скоростью 40 град/мин до $200{ }^{\circ} \mathrm{C}$ и дальнейшее увеличение температуры со скоростью 12,5 град/мин до $300{ }^{\circ} \mathrm{C}$ с выдержкой при конечной температуре 6 минут. Газ-носитель гелий. Режим постоянного потока "Constant flow" 1,3 мл/мин. Температура инжектора $260{ }^{\circ} \mathrm{C}$, устройства сопряжения с детектором $280{ }^{\circ} \mathrm{C}$. Ввод пробы без разделения потока со сбросом избытка через 1 минуту в отношении потоков 1:100 (Split). Условия детектирования: режим сканирования ионов в интервале 40-400 ат. ед. массы. Запись хроматограммы спустя 3 минуты после ввода пробы.

О-Производные 5,7-дибром-8-оксихинолина 2-6 (схема 1) получены по методу [6]. 
<smiles>Oc1c(Br)cc(Br)c2cccnc12</smiles><smiles>C=CCOc1c(Br)cc(Br)c2cccnc12</smiles><smiles>C=C(C)COc1c(Br)cc(Br)c2cccnc12</smiles><smiles>C#CCOc1c(Br)cc(Br)c2cccnc12</smiles><smiles>COc1c(Br)cc(Br)c2cccnc12</smiles><smiles>COc1c(Br)cc(Br)c2cccnc12</smiles><smiles>C=CCc1cc(Br)c2cccnc2c1O</smiles><smiles>C=C(C)Cc1cc(Br)c2cccnc2c1O</smiles>

Схема 1. Структурные формулы исследуемых соединений

\section{Обсуждение результатов}

При исследовании методом хроматомасс-спектрометрии (ХMC) вещество подвергается термическому воздействию при $200-250^{\circ} \mathrm{C}$. При этих температурах в аллилариловых эфирах происходит перегруппировка Кляйзена [7].

При исследовании 5,7-дибром-8-аллилоксихинолина методом ХМС нами неожиданно, помимо соединения 2, обнаружено вещество, содержащее один атом брома и соответствующее 5-бром-7-аллил-8-гидроксихинолину.

Об этом свидетельствуют пики изотопных молекулярных ионов с $m / z=265$ и 263 одинаковой интенсивности, пик иона [M-CO] $]^{+}$и пик иона $[\mathrm{M}-\mathrm{HCO}]^{+}$, характерные для фенолов [7].

Аналогично при исследовании 5,7-дибром-8-металлиоксихинолина (рис. 1) нами обнаружен 5-бром-7-металлил-8-гидроксихинолин с $m / z=279$ и 277 (рис. 2).

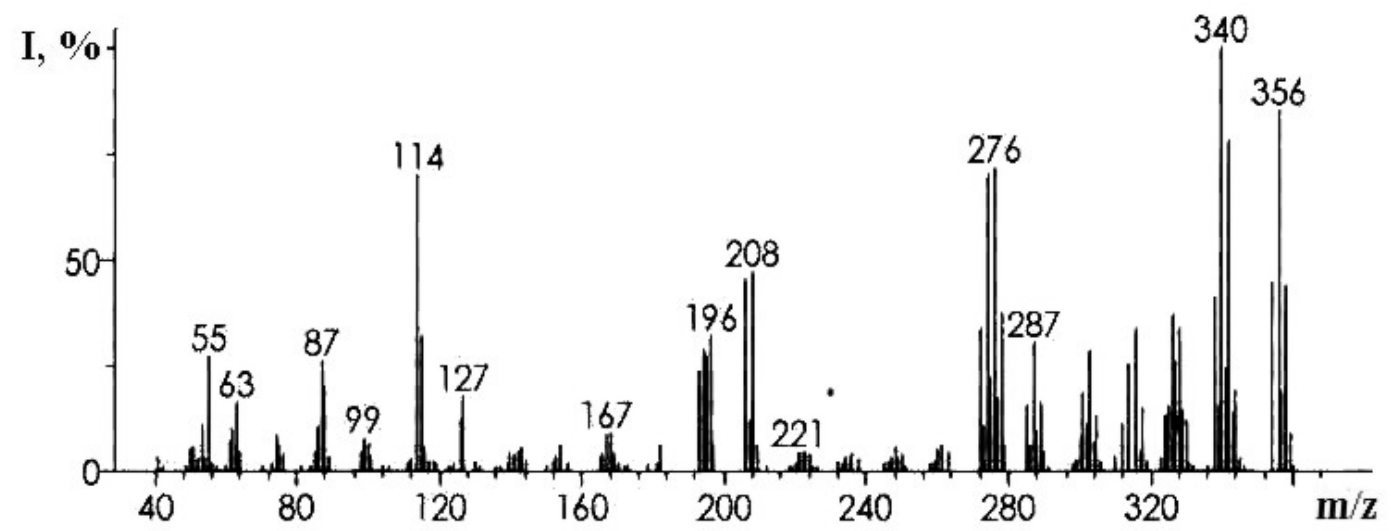

Рис. 1. Масс-спектр 5,7-дибром-8-металлилоксихинолина 


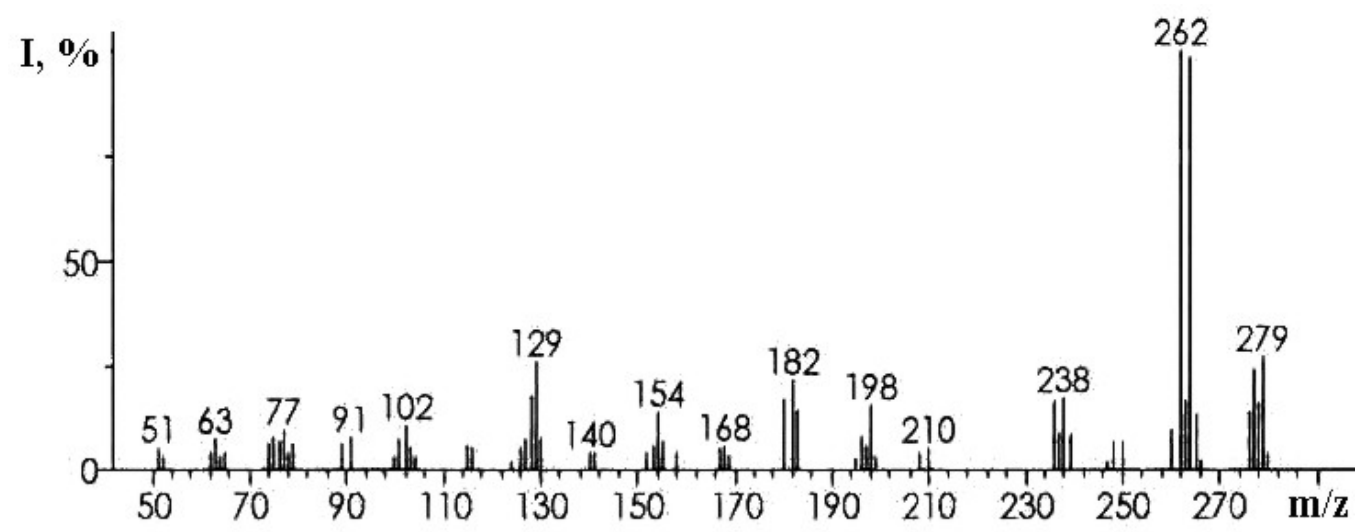

Рис. 2. Масс-спектр 5-бром-7-металлил-8-гидроксихинолина

По-видимому, вначале из эфира 2 образуется 5,7-дибром-7-аллил-7,8-дигидро-8-хинолон (9), который превращается в 5-бром-7-аллил-8-бромоксихинолин (10), и далее, под действием протоносодержащих растворителей (вода, 2-пропанол) превращается в 5-бром-7-аллил-8гидроксихинолин (схема 2).<smiles>C=CCOc1c(Br)cc(Br)c2ccc(CC=CC)nc12</smiles>

Схема 2. Перегруппировка 5,7-дибром-8-оксихинолина

В отличие от 5,7-дибром-8-аллилоксихинолина и 5,7-дибром-8-металлиоксихинолина, 5,7-дибром-8-метоксихинолин, 5,7-дибром-8-этоксихинолин и $\quad$ 5,7-дибром-8-пропаргилоксихинолин, не содержащие аллильную группу, не дают при исследовании методом ХМС монобромпроизводные 8-гидроксихинолина.

Масс-спектрометрические данные приведены в таблице.

Данные масс-спектров исследованных соединений

\begin{tabular}{|c|c|}
\hline Соединение & Характеристики ионов: $m / z(I, \%)$ \\
\hline $\begin{array}{c}\mathbf{1} \\
\left(\mathrm{C}_{9} \mathrm{H}_{5} \mathrm{NOBr}_{2}\right) \\
\end{array}$ & $\begin{array}{l}305(51), 303(100), 301(51)[\mathrm{M}]^{+}, 275[\mathrm{M}-\mathrm{CO}]^{+} .(15), 195\left[\mathrm{C}_{8} \mathrm{H}_{5} \mathrm{NBr}\right]^{+}(31), 143[\mathrm{M}- \\
\left.\mathrm{Br}_{2}\right]^{+}(10), 115(33), 87(13)\end{array}$ \\
\hline$\stackrel{2}{\left(\mathrm{C}_{12} \mathrm{H}_{9} \mathrm{NOBr}_{2}\right)}$ & $\begin{array}{l}345(5), 343(10), 341(5)[\mathrm{M}]^{+}, 342[\mathrm{M}-\mathrm{H}]^{+}(34), 328\left[\mathrm{M}^{-} \mathrm{CH}_{3}\right]^{+}(20), 326[\mathrm{M}-\mathrm{OH}]^{+} \\
(40), 314[\mathrm{M}-\mathrm{CHO}]^{+}(61), 287\left[\mathrm{C}_{9} \mathrm{H}_{5} \mathrm{NBr}_{2}\right]^{+}(20), 274\left[\mathrm{C}_{8} \mathrm{H}_{4} \mathrm{NBr}_{2}\right]^{+}(66), 262[\mathrm{M}-\mathrm{Br}]^{+} \\
(31), 249\left[\mathrm{C}_{12} \mathrm{H}_{9} \mathrm{NBr}\right]^{+}(47), 236[\mathrm{C} 10 \mathrm{H} 6 \mathrm{NOBr}]^{+}(11), 208(39), 195\left[\mathrm{C}_{8} \mathrm{H}_{5} \mathrm{NBr}\right]^{+}(25), \\
182\left[\mathrm{C}_{12} \mathrm{H}_{8} \mathrm{NOO}\right]^{+}(14), 166(14), 154\left[\mathrm{C}_{11} \mathrm{H}_{8} \mathrm{~N}\right]^{+}(31), 127(29), 114(100), 87(46), 74 \\
(17), 63(44), 41(39)\end{array}$ \\
\hline $\begin{array}{c}\mathbf{3} \\
\left(\mathrm{C}_{13} \mathrm{H}_{9} \mathrm{NOBr}_{2}\right)\end{array}$ & 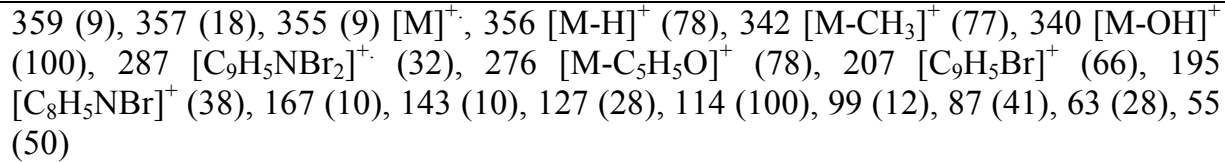 \\
\hline$\stackrel{4}{\left(\mathrm{C}_{12} \mathrm{H}_{7} \mathrm{NOBr}_{2}\right)}$ & $\begin{array}{l}343(10), 341(18), 339(10)[\mathrm{M}]^{+}, 340[\mathrm{M}-\mathrm{H}]^{+}(19), 312[\mathrm{M}-\mathrm{CHO}]^{+}(35), 287[\mathrm{M}- \\
\left.\mathrm{C}_{3} \mathrm{H}_{3} \mathrm{O}\right]^{+}(34), 274\left[\mathrm{M}-\mathrm{C}_{4} \mathrm{H}_{3} \mathrm{O}\right]^{+} \cdot(54), 261[\mathrm{M}-\mathrm{Br}]^{+}(35), 232\left[\mathrm{C}_{11} \mathrm{H}_{6} \mathrm{NBr}\right]^{+}(14), 207 \\
{\left[\mathrm{C}_{9} \mathrm{H}_{5} \mathrm{Br}\right]^{+}(30), 195\left[\mathrm{C}_{8} \mathrm{H}_{5} \mathrm{NBr}\right]^{+}(28), 154\left[\mathrm{M}-\mathrm{C}_{2} \mathrm{H}_{5} \mathrm{Br}\right]^{+}(26), 127(20), 114(100), 87} \\
(39), 74(11), 63(33), 50(10), 39(35)\end{array}$ \\
\hline
\end{tabular}




\begin{tabular}{|c|c|}
\hline Соединение & Характеристики ионов: $m / z(I, \%)$ \\
\hline $\begin{array}{c}\mathbf{5} \\
\left(\mathrm{C}_{10} \mathrm{H}_{7} \mathrm{NOBr}_{2}\right)\end{array}$ & $\begin{array}{l}319(18), 317(33), 315(18)[\mathrm{M}]^{+}, 289[\mathrm{M}-\mathrm{CO}]^{+} \cdot(32), 287\left[\mathrm{M}^{+} \mathrm{CH}_{2} \mathrm{O}\right]^{+}(65), 236[\mathrm{M}- \\
\mathrm{Br}^{+}(13), 207\left[\mathrm{C}_{9} \mathrm{H}_{5} \mathrm{Br}\right]^{+}(64), 195\left[\mathrm{C}_{8} \mathrm{H}_{5} \mathrm{NBr}\right]^{+}(15), 143(14), 128(47), 114(85), 104 \\
(33), 87(46), 74(28), 63(100), 50(37), 40(21)\end{array}$ \\
\hline $\begin{array}{c}\mathbf{6} \\
\left(\mathrm{C}_{11} \mathrm{H}_{9} \mathrm{NOBr}_{2}\right)\end{array}$ & 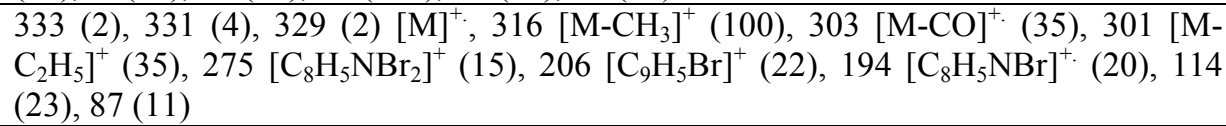 \\
\hline $\begin{array}{c}7 \\
\left(\mathrm{C}_{12} \mathrm{H}_{10} \mathrm{NOBr}\right)\end{array}$ & $\begin{array}{l}265(28), 263(33)[\mathrm{M}]^{+}, 249\left[\mathrm{M}_{-} \mathrm{CH}_{3}\right]^{+}(17), 248[\mathrm{M}-\mathrm{OH}]^{+}(100), 236\left[\mathrm{M}-\mathrm{C}_{2} \mathrm{H}_{4}\right]^{+} \\
(13), 182\left[\mathrm{C}_{12} \mathrm{H}_{8} \mathrm{NO}\right]^{+}(16), 166\left[\mathrm{C}_{12} \mathrm{H}_{9} \mathrm{~N}\right]^{+}(19), 154\left[\mathrm{M}-\mathrm{C}_{2} \mathrm{H}_{5} \mathrm{Br}\right]^{+}(26), 129(22), 102 \\
(15), 77(13)\end{array}$ \\
\hline $\begin{array}{c}\mathbf{8} \\
\left(\mathrm{C}_{13} \mathrm{H}_{10} \mathrm{NOBr}\right)\end{array}$ & 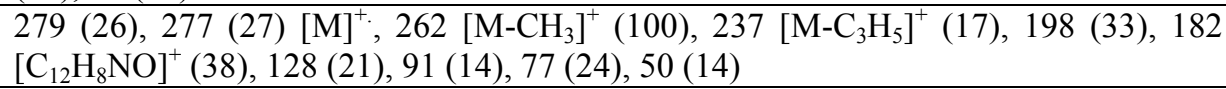 \\
\hline
\end{tabular}

*Указаны пики с интенсивностями выше 10 \%, за исключением пиков молекулярных ионов.

В масс-спектрах всех исследуемых соединений 1-8, присутствуют пики молекулярных ионов $[\mathrm{M}]^{+}$. В спектрах соединений $2,3,7$ и 8 , наблюдается сигналы иона $[\mathrm{M}-\mathrm{H}]^{+}$, и иона $\left[\mathrm{M}-\mathrm{CH}_{3}\right]^{+}$. что связано с образованием устойчивых тиазинохинолиниевых систем 11 и 12 (схема 3).

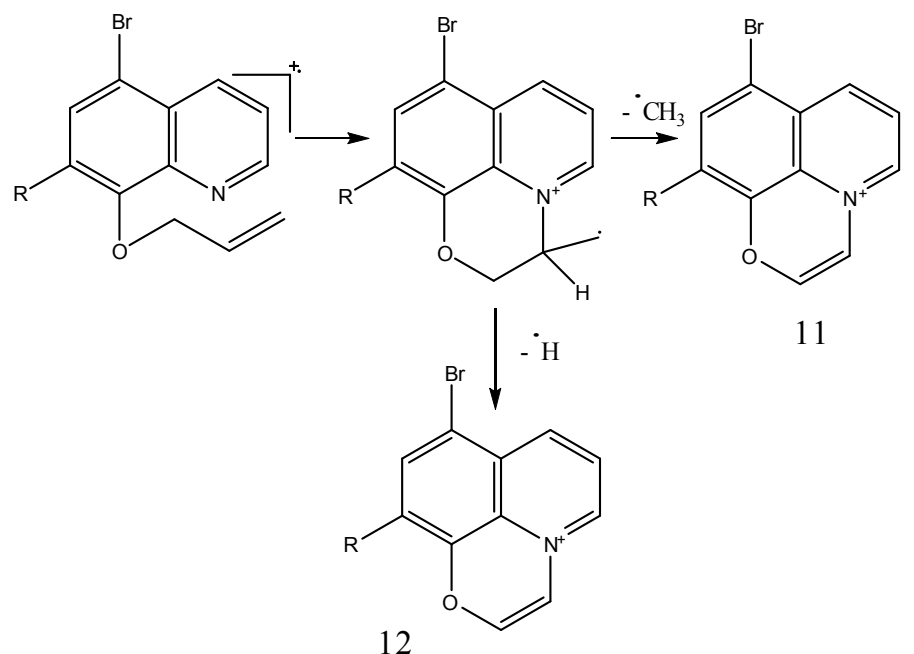

$\mathrm{R}=\mathrm{H}, \mathrm{Br}$

Схема 3. Фрагментация 5,7-дибром-8-аллилоксихинолина и 5-бром-7-аллил-8-гидроксихинолина

В масс-спектре 5,7-дибром-8-пропаргилоксихинолина также имеется пик $[\mathrm{M}-\mathrm{H}]^{+}$, что, на наш взгляд, связано с образованием устойчивой оксопиридохинолиниевой системы 13 (схема 4).<smiles>C#CCOc1c(Br)cc(Br)c2cc(CC)cnc12</smiles>

4<smiles>Brc1cc(Br)c2ccc[n+]3c2c1OCC=C3</smiles><smiles>CCCCCC=CC=O</smiles><smiles>Cc1cc(Br)c2ccc[n+]3c2c1C(=O)C=C3</smiles>

13 
Во всех соединениях, за исключением 5,7-дибром-8-оксихинолина, имеются пики, соответствующие разрывам алифатической и ароматической связей С-О. Для соединений $\mathbf{1}, \mathbf{5}$ и $\mathbf{6}$ характерен сигнал иона $[\mathrm{M-CO}]^{+}$с $\mathrm{m} / z=275, \mathrm{~m} / z=289$ и $\mathrm{m} / z=303$ соответственно.

В спектрах соединений 2,3 и 7 присутствует сигнал иона $[\mathrm{M}-\mathrm{OH}]^{+}(\mathrm{m} / z=326, m / z=340$ и $m / z=248$ соответственно), которые свидетельствуют об образовании пиридохинолиниевых систем 14 a-b (схема 5). Для 5,7-дибром-8-аллилоксихинолин и 5,7-дибром-8-металлилоксихинолина эти пики максимальны.<smiles></smiles><smiles>[2H]c1cc(Br)c2ccc[n+](CC3CO3)c2c1</smiles><smiles>Brc1cc(Br)c2ccc[n+]3c2c1C=CC3</smiles><smiles></smiles>

14 a-c

$\mathrm{R}=\mathrm{H}, \mathrm{Br}$

Схема 5. Фрагментации с элиминированием гидроксильного радикала

В спектрах соединений $\mathbf{2 ,}, \mathbf{3}, \mathbf{4}$ и $\mathbf{8}$ имеется сигнал иона $\left[\mathrm{M}-\mathrm{OCH}_{3}\right]^{+}$обусловленное образованием пирроло[3,2,1-ij]хинолиниевых систем 15 a-d (схема 6).

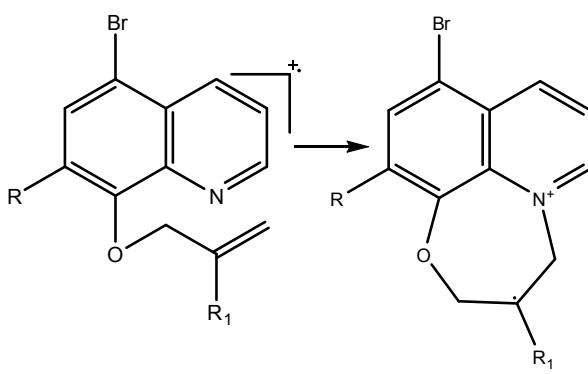<smiles>Brc1cc(Br)c2ccc[n+](CC3(Br)CO3)c2c1</smiles><smiles></smiles>

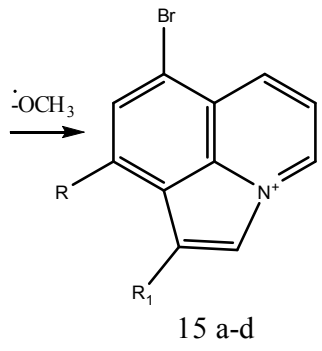

$$
\mathrm{R}=\mathrm{H}, \mathrm{Br} ; \mathrm{R}_{1}=\mathrm{H}, \mathrm{CH}_{3}
$$

Схема 6. Фрагментация с элиминированием метоксильного радикала

\section{Заключение}

Найдено, что 5,7-дибром-8-аллилоксихинолин и 5,7-дибром-8-металлиоксихинолин в условиях хроматомасс-спектрометрических исследований превращаются в 5-бром-7-аллил-8гидроксихинолин и 5-бром-7-металлил-8-гидроксихинолин соответственно. Установлено, что соединения 4, 5 и 6, не содержащие аллильную группу, не претерпевают в аналогичных условиях превращений. 


\section{Литература}

1. Машковский, М.Д. Лекарственные средства. В 2 ч. / М.Д. Машковский. -12-е изд. - М.: Медицина, 1993. - Ч. 2. - 345 с.

2. Солдатенков, А.Т. Основы органической химии лекарственных веществ / А.Т. Солдатенков, Н.М. Колядина, И.В. Шендрик. - 2-е изд. - М.: Мир, 2003. - 192 с.

3. Synthesis and antiproliferative activity of 8-hydroxyquinoline derivatives containing a 1,2,3triazole moiety / L.B. de O.Freitas, T.F. Borgati, R.P. de Freitas et al. // European Journal of Medicinal Chemistry. - 2014. - V. 84. - P. 595-604.

4. Вульфсон, Н.С. Масс-спектрометрия органических соединений / Н.С. Вульфсон, В.Г. Заикин, А.И. Микая. - М.: Химия, 1986. - 312 с.

5. Лебедев, А.Т. Масс-спектрометрия в органической химии / А.Т. Лебедев. - М.: Бином, 2003. $-493 \mathrm{c}$.

6. Ким, Д.Г. Галогенциклизация 8-аллилоксихиноинов / Д.Г. Ким, Э.Р. Закирова // Известия вузов. Сер. «Химия и химическая технология». - 1993. - Вып. 3 - С. 46-48.

7. Темникова, Т.И. Молекулярные перегруппировки в органической химии / Т.И. Темникова, С.Н. Семенова. - Л.: Химия, 1983. - 256 с.

Ким Дмитрий Гымнанович - доктор химических наук, профессор, кафедра органической химии, химический факультет, Южно-Уральский государственный университет. 454080, г. Челябинск, пр. им. В.И. Ленина, 76. E-mail:kim_dg48@mail.ru

Василенко Анна Владимировна - соискатель ученой степени кандидата наук кафедры органической химии, химический факультет, Южно-Уральский государственный университет. 454080, г. Челябинск, пр. им. В.И. Ленина, 76. E-mail: LAV_chem@mail.ru

Мелентьев Алексей Борисович - кандидат химических наук, заведующий судебнохимическим отделением Челябинского областного бюро судебно-медицинской экспертизы. 454076, г. Челябинск, ул. Варненская, 4-б. E-mail: amelentyev@sme74.ru

Поступила в редакцию 9 декабря 2015 г.

DOI: $10.14529 /$ chem160102

\section{STUDY OF 5,7-DIBROMO-8-HYDROXYQUINOLINE O-DERIVATIVES BY GAS CHROMATOGRAPHY-MASS SPECTROMETRY}

D.G. Kim ${ }^{1}, k i m \_d g 48 @ m a i l . r u$

A.V.Vasilenko $\overline{1}$, LAV_chem@mail.ru

A.B. Melentyev', amelentyev@sme74.ru

${ }^{1}$ South Ural State University, Chelyabinsk, Russian Federation

${ }^{2}$ Chelyabinsk Regional Forensic Medicine Bureau, Chelyabinsk, Russian Federation

It has been found that under conditions of gas chromatography-mass spectrometry study both 8-allyloxy-5,7-dibromoquinoline and 5,7-dibromo-8-methallyloxyquinoline are decomposed to form 7-allyl-5-bromo-8-hydroxyquinoline and 5-bromo-7-methallyl-8hydroxyquinoline, respectively.

Keywords: 5,7-dibromo-8-allyl(methallyl)hydroxyquinoline, 5-bromo-7-allyl(methallyl)-8hydroxyquinoline, 5,7-dibromo-8-methyl(ethyl)hydroxyquinoline, 5,7-dibromo-8-propargyloxyquinoline, chromatography-mass spectrometry, thermal reaction. 


\section{References}

1. Mashkovskiy M.D. Lekarstvennye sredstva [Chemistry Drugs]. 2 part. $12^{\text {th }}$ ed. Moscow, Medicina Publ., 1993, p. 345.

2. Soldatenkov A.T., Kolyadina N.M., Shendrik I.V. Osnovy organicheskoy khimii lekarstvennykh sredstv [Fundamentals of Organic Chemistry Drugs]. Moscow, Mir Publ., 2003. 192 p.

3. De O. Freitas L.B., Borgati T.F., de Freitas R.P., Ruiz A.L.T.G., Marchetti G.M., de Carvalho J.E., da Cunha E.F.F., Romalho T.C., Alves R.B. Synthesis and Antiproliferative Activity of 8-Hydroxyquinoline Derivatives Containing a 1,2,3-triazole Moiety. European Journal of Medicinal Chemistry. 2014. no. 84, pp. 595-604. DOI: 10.1016/j.ejmech.2014.07.061.

4. Wul'fson N.S., Zaikin V.G., Mikaya A.I. Mass-spektrometriya organicheskikh soedineniy [Mass Spectrometry of Organic Compounds]. Moscow, Khimiya Publ., 1986. 312 p.

5. Lebedev A.T. Mass-spektrometriya v organicheskoy khimii [Mass Spectrometry in Organic Chemistry]. Moscow, Binom Publ., 2003. 493 p.

6. Kim D.G., Zakirova E.R. [Halogencyclization of 8-Allyloxyquinolines] Chemistry and Chemical Technology, 1993. no. 3, pp. 46-48. (in Russ.)

7. Temnikova T.I., Semenova S.N. Molekulyarnye peregruppirovki v organicheskoy khimii [Molekular Regroupings to Organic Chemistry]. Leningrad, Khimiya Publ., 1983. 256 p.

Received 9 December 2015

\section{ОБРАЗЕЦ ЦИТИРОВАНИЯ}

Ким, Д.Г. Исследование о-производных 5,7-дибром-8оксихинолина методом хроматомасс-спектрометрии / Д.Г. Ким, А.В. Василенко, А.Б. Мелентьев // Вестник ЮУрГУ. Серия «Химия». - 2016. - Т. 8, № 1. - С. 13-19. DOI: $10.14529 /$ chem160102

\section{FOR CITATION}

Kim D.G., Vasilenko A.V., Melentyev A.B. Study of 5,7-Dibromo-8-Hydroxyquinoline O-Derivatives by Gas Chromatography-Mass Spectrometry. Bulletin of the South Ural State University. Ser. Chemistry. 2016, vol. 8, no. 1, pp. 13-19. DOI: $10.14529 /$ chem 160102 